\title{
Efficacy and abuse potential of opioid analgesics and the treatment of chronic noncancer pain
}

\author{
Andrew C Darke PhD, John H Stewart MSc
}

\begin{abstract}
AC Darke, JH Stewart.
Efficacy and abuse potential of opioid analgesics and the treatment of chronic noncancer pain.

Pain Res Manage 1999;4(2):104-109.

While the role of opioid analgesics has been established in the treatment of cancer pain, reservations persist about appropriate use in patients with chronic noncancer pain. Recent evidence from controlled clinical trials supports the effectiveness of opioids for treating noncancer pain of varying etiologies.

The safety of opioids in noncancer patients has been an area of controversy because of confusion between physical dependence, which develops in all patients receiving opioids chronically, and addiction, which is a behavioural diagnosis that is rarely made in patients appropriately treated with opioids for pain.

Abuse by secondary recipients of opioids is well documented and arises as a result of diversion by primary recipients, doubledoctoring, forgery and theft. The frequency of forgery and theft of different opioids appears to be largely related to the corresponding number of legitimate prescriptions.

While it is legitimate medical practice to prescribe opioid analgesics to patients with chronic noncancer pain, there is clear evidence that prescribing is affected by concerns of regulatory sanctions. Recent guidelines, including most recently comprehensive guidelines issued by the Canadian Pain Society, should help to reduce inappropriate undertreatment because of such concerns.
\end{abstract}

Key Words: Abuse; Addiction; Chronic; Noncancer; Opioid; Pain

\section{Efficacité des opiacés et risque de dépendance à leur endroit, dans le traitement de la douleur chronique non liée au cancer}

Si le rôle des opiacés a été établi dans le traitement de la douleur liée au cancer, on entretient certaines réserves lorsqu'il est question de leur emploi approprié chez des patients dont les douleurs chroniques ne sont pas liées au cancer. Selon des preuves récentes tirées d'essais contrôlés, les opiacés soulageraient efficacement divers types de douleurs non liées au cancer. L'innocuité des opiacés chez les patients non cancéreux a fait l'objet de controverses en raison de la confusion que soulèvent la dépendance physique, qui s'installe chez tous les patients traités à long terme aux opiacés, et la toxicomanie, qui est un diagnostic comportemental rarement posé chez des patients souffrants qui sont traités au opiacés de façon appropriée. La dépendance chez les receveurs secondaires d'opiacés est bien documentée et dérive d'une diversion de la part des receveurs principaux, du «magasinage » de médecins, de la fraude et du vol. La fréquence des fraudes et des vols de différents opiacés semble fortement proportionnelle au nombre d'ordonnances légitimes.

S'il est normal sur le plan de la pratique médicale de prescrire des opiacés aux patients souffrant de douleurs chroniques non liées au cancer, il est clair, preuve à l'appui, que les ordonnances sont affectées par la crainte des sanctions disciplinaires. La publication de directives récentes, y compris les récentes normes plus globales émises par la Société canadienne pour le traitement de la douleur, devrait contribuer à résoudre les problèmes de traitements inadéquats inhérents à la situation actuelle.
$\mathrm{O}$ ver the past 25 years, the use of morphine and other opioids to control cancer pain has become standard medical practice and is supported by important groups such as the American Medical Association, American Pain Society, Health Canada and the World Health Organization. The appropriateness of opioids for the treatment of chronic noncancer pain is not as well established due to uncertainty about their effectiveness in many chronic pain conditions, concern that their use may promote abuse or addiction and prescribers' fear of sanction by medical regulatory bodies. 
The purpose of the present review is to summarize the evidence demonstrating the efficacy of opioids, as well as their limitations, in the treatment of noncancer pain, to offer a perspective on the many issues surrounding their use for this indication, and to discuss the current extent and potential for abuse of these drugs.

\section{EFFICACY OF OPIOID ANALGESICS IN PATIENTS WITH CHRONIC NONCANCER PAIN}

Numerous anecdotal reports of the efficacy of opioid analgesics in the treatment of noncancer pain have recently been supplemented with data from controlled clinical trials and support the view expressed by many experts that there is an important role for opioids in the treatment of chronic noncancer pain (1-5).

Recent controlled trials using morphine (6), oxycodone (7) and codeine $(8,9)$ have convincingly demonstrated efficacy in terms of reduction of pain scores and/or pain disability indexes, in a variety of musculoskeletal and neuropathic pains. In a study of controlled-release morphine (6), patients with chronic regional soft-tissue or musculoskeletal pain were treated with a mean dose of $127 \mathrm{mg} /$ day or active placebo (benztropine) for three weeks during which the dose was gradually titrated, followed by six weeks at a stable dose. Significantly lower pain scores were found in patients treated with morphine in the first period of this crossover trial, but no functional improvement was noted. No evidence of addiction was found in these patients who received morphine for over two months.

In a crossover study of patients with post-herpetic neuralgia who were treated with controlled-release oxycodone or placebo for four weeks, a significant improvement in steady pain, paroxysmal pain and allodynia was demonstrated at a mean oxycodone dose of $45 \mathrm{mg} / \mathrm{day}$ (7). Additionally, painrelated disability improved during oxycodone treatment. This study is the first placebo controlled study to establish the efficacy of chronic opioid treatment in a model of neuropathic pain.

In two short term studies of controlled-release codeine, in patients with chronic arthritic or back pain, significant reductions in pain score relative to placebo (8) or as required dosing of acetaminophen plus codeine (9) were demonstrated at mean doses of $273 \mathrm{mg} /$ day and $200 \mathrm{mg} /$ day, respectively. A significant improvement in pain-related disability was also demonstrated on controlled-release codeine compared with placebo.

In two recent studies, well defined patient populations with osteoarthritis were treated with controlled-release codeine (10) or oxycodone (11) in comparison with placebo. At mean doses of $159 \mathrm{mg} /$ day codeine or $40 \mathrm{mg} /$ day oxycodone, significant reductions in pain were demonstrated.

These studies in chronic noncancer pain employed scheduled dosing of controlled-release formulations of opioids, which avoid rapidly fluctuating plasma concentrations and may be less likely to lead to abuse (12). The less frequent dosing schedule provided by these formulations may help break the association between dosing and pain relief, and may be less likely to result in any short lived euphoria associated with the peak blood levels that occur shortly after taking regular, immediate-release formulations.

\section{PATIENT ABUSE OF ORAL OPIOID ANALGESICS}

Distinction is required among the terms abuse, addiction and physical dependence. Abuse is defined as use for nontherapeutic purposes; addiction is a diagnosis based on a pattern of compulsive drug seeking behaviour; and physical dependence is manifested as a withdrawal reaction that commonly occurs on abrupt termination of chronic opioid treatment. The Diagnostic and Statistical Manual of Mental Disorders, Fourth Edition (DSM-IV) (13) requires three of the following criteria to be present in the same 12-month period for a diagnosis of current opioid dependence to be made:

\section{Marked tolerance}

Withdrawal symptoms

Use of larger amounts or for longer periods than intended

Persistent desire or lack of success in reducing use

Large amount of time spent in obtaining the substance

Use interferes with social occupational or recreational activities

\section{Continued use despite harm}

In addition, the term 'pseudoaddiction' has been used to describe drug-seeking behaviour that is motivated by a genuine need to obtain adequate pain control.

Almost all patients receiving chronic opioid treatment become somewhat physically dependent and, therefore, may show symptoms of withdrawal if opioid administration is abruptly stopped rather than gradually tapered. However, the majority of patients who no longer require opioids for pain control can successfully have their daily doses reduced and eliminated over a short period of time (3).

In contrast to physical dependence, which can be managed by a gradual tapering of the opioid dosage, addiction is suggested by observation of a number of typical signs (14) (Table 1).

Based on survey data involving large numbers of patients treated with opioids for pain, it has been concluded that the risk of addiction is extremely low in patients who receive opioid analgesics appropriately for pain management (15). In a survey by the Boston Collaborative Drug Surveillance Program, 11,882 patients were identified who had received at least one opioid preparation. Of these patients, only four were identified as having an addiction problem without a prior history of addiction (16). Similarly, a survey of burn units failed to document a case of iatrogenic addiction in approximately 10,000 patients who received narcotic analgesics (17). However, other studies of pain clinic patients receiving opioids 
TABLE 1

Signs of opioid addiction

\begin{tabular}{cc}
$\begin{array}{c}\text { Preoccupation with use/ } \\
\text { drug-seeking behaviour }\end{array}$ & Loss of control \\
\hline $\begin{array}{c}\text { Unwilling to try to taper opioid } \\
\text { use when alternative pain } \\
\text { treatments offered }\end{array}$ & $\begin{array}{c}\text { Cannot take medications as } \\
\text { prescribed }\end{array}$ \\
$\begin{array}{c}\text { Reports no relief by any } \\
\text { interventions other than } \\
\text { opioids }\end{array}$ & $\begin{array}{c}\text { Frequently runs out of medications } \\
\text { before renewal due } \\
\text { Repeatedly reports lost or destroyed } \\
\text { prescriptions or medications }\end{array}$ \\
$\begin{array}{c}\text { Strong preference for short- } \\
\text { acting or bolus-dose } \\
\text { medications }\end{array}$ & $\begin{array}{c}\text { Breaks contract with provider (uses } \\
\text { several pharmacies, does not } \\
\text { Obtains prescriptions from } \\
\text { multiple sources }\end{array}$ \\
$\begin{array}{c}\text { Uses street drugs } \\
\text { Noncomply with other treatments, } \\
\text { treatment recommendations other }\end{array}$ & $\begin{array}{c}\text { Continued use despite } \\
\text { adverse consequences }\end{array}$ \\
& $\begin{array}{c}\text { Decreased level of function despite } \\
\text { apparent analgesia }\end{array}$ \\
& $\begin{array}{c}\text { Persistent side effects of opioids } \\
\text { such as somnolence, sedation } \\
\text { and euphoria }\end{array}$ \\
\hline
\end{tabular}

Reproduced with permission from reference 14

chronically have identified evidence of opioid abuse in this population, and clinicians, therefore, remain concerned over the possibility that a patient to whom opioids are appropriately prescribed will become an abuser, as well as the possibility that a patient could be a current abuser of opioids (18).

Few studies have looked quantitatively at the abuse of oral opioids. In a recent study carried out at the Addiction Research Foundation of Ontario (19), the characteristics and predisposing factors of 58 patients consecutively admitted with a diagnosis of severe oral opioid dependence defined according to DSM-IIIR criteria were examined. The mean duration of opioid use at the current dose was 81 months (range seven to 330 months), and the primary opioids of abuse were codeine $(52 \%)$ and oxycodone $(40 \%)$, with a smaller proportion abusing hydromorphone $(6.9 \%)$ or morphine $(1.7 \%)$. Conclusions about the inherent abuse potential of different opioids based on such data may be misleading. The frequency of abuse may be primarily reflective of the extent of legitimate use, and these percentages should, therefore, be interpreted within the framework of the percentage of total oral opioid prescriptions that these agents represent (Table 2).

Although the majority of patients in the study of Busto et al (19) had initially used opioids for the treatment of pain (migraine 22\%; other pain 50\%), many also had a strong family history of substance abuse; $52 \%$ reported at least one close family member with problems with alcohol and/or other drugs.

While the possibility of patient abuse of opioid analgesics for pain management cannot be totally discounted, initiatives to minimize this possibility include the development and dissemination of a Screening Instrument for Substance Abuse Potential (SISAP), a tool designed to identify patients most at risk of opioid abuse (20), as well as other tools such as patient
TABLE 2

Prescriptions for oral opioid formulations in Canada, 1998

\begin{tabular}{lcc}
\hline & \multicolumn{2}{c}{ Prescriptions } \\
& $\begin{array}{c}\text { Number } \\
(\times \mathbf{1 0 0 0})\end{array}$ & $\begin{array}{c}\text { Percentage of } \\
\text { total }\end{array}$ \\
\hline $\begin{array}{l}\text { Codeine and codeine } \\
\quad \text { combinations }\end{array}$ & 8025 & 78.5 \\
$\begin{array}{l}\text { Oxycodone and oxycodone } \\
\quad \text { combinations }\end{array}$ & 903 & 8.8 \\
$\begin{array}{l}\text { Morphine } \\
\text { Hydromorphone }\end{array}$ & 525 & 5.1 \\
All others* & 266 & 2.6 \\
\hline
\end{tabular}

*Synthetic noninjectables (eg, meperidine, pentazocine, anileridine). Data from reference 24

contracts covering initiation, management and termination of opioid treatment. The SISAP recognizes that the mere exposure to opioids does not lead to addiction and/or abuse and that it is highly unlikely for a person with no previous history of alcohol or drug abuse to become addicted to prescribed opioids. The SISAP is a five-item screening questionnaire designed to identify individuals who are at risk of abusing opioids, allowing clinicians to pay close attention to patients with an elevated risk of addiction while being less concerned about addiction and abuse in the majority of patients who are not at risk.

Notwithstanding the concern over providing opioid analgesics to patients who are at risk of abuse, literature supporting the use of opioids in this setting, subject to specific safeguards, now exists (21).

\section{NATURE AND SOURCE OF ABUSED ORAL OPIOIDS}

It is evident that prescription drugs are widely available for purchase on the street, and it is, therefore, uncertain whether the primary abusers of opioid analgesics are those legitimately receiving opioids for pain control. In a recent survey of buyers and users in Vancouver, British Columbia, the availability of a wide range of prescription opioid analgesics and sedative hypnotics was documented (22). The authors noted that drugs with high street value were strong narcotics whose availability in British Columbia may be limited by the triplicate prescription program. In addition, the extent of use of various drugs in the street may be correlated with the extent of legitimate use because this would be expected to increase the supply available for diversion from patients or pharmacies. It is, therefore, likely that the relationship among supply, demand and price is not a simple one and it does not provide a basis for concluding that the street value of various opioid analgesics is reflective of their abuse potential.

There are several possible routes whereby opioids intended for therapeutic use enter the abuse chain. 
TABLE 3

Forged opioid prescriptions in Canada, 1994

\begin{tabular}{|c|c|c|c|}
\hline Opioid & $\begin{array}{l}\text { Total prescriptions dispensed } \\
(\times 1000)(24)\end{array}$ & $\begin{array}{l}\text { Estimated prescriptions forged } \\
(\times 1000)(23)\end{array}$ & $\begin{array}{c}\text { Forged prescriptions as percentage } \\
\text { of total prescriptions }\end{array}$ \\
\hline Codeine & 7904 & 0.498 & 0.006 \\
\hline Oxycodone & 503 & 0.280 & 0.06 \\
\hline \multicolumn{4}{|l|}{ Hydrocodone } \\
\hline Tablet & 18 & - & - \\
\hline Liquids & 510 & - & - \\
\hline Total & 528 & 0.053 & 0.01 \\
\hline \multicolumn{4}{|l|}{ Morphine } \\
\hline Sustained release & 173 & - & - \\
\hline Immediate release & 51 & - & - \\
\hline Total & 224 & 0.030 & 0.01 \\
\hline Hydromorphone & 97 & 0.069 & 0.07 \\
\hline Meperidine & 193 & 0.054 & 0.03 \\
\hline Pentazocine & 128 & 0.029 & 0.02 \\
\hline
\end{tabular}

Data from references 23,24

\section{Opioid diversion}

Patients who receive opioid prescriptions for pain legitimately may elect to divert a proportion of their prescription for profit. This may become evident to physicians through its association with other addictive behaviours. Some patients may require high doses of opioids to achieve adequate pain relief, but doses that appear to be high in relation to the level of pain or pain history may be an indicator of diversion. Because judgement in this area is undoubtedly difficult, the need for more continuing education of physicians in pain management is evident.

\section{Double doctoring}

Double doctoring may involve abuse by the primary recipient or diversion to a third party. Data on the relative incidence of these two alternatives are not available, but in a recent study of patients admitted to the Medical Unit of the Addiction Research Foundation of Ontario with a diagnosis of opioid dependence, $39 \%$ admitted to obtaining opioids for their own use by visiting more than one doctor, while $26 \%$ purchased their opioids on the street (18).

\section{Forged prescriptions}

Based on the Canadian Profile, Alcohol, Tobacco and Other Drugs compiled by the Canadian Centre on Substance Abuse, Addiction Research Foundation of Ontario in 1997 (23), the total number of forged prescriptions in 1994 was as shown in Table 3. Also included is the estimated number of prescriptions for each opioid derived from IMS Health data (24). The proportion of forged prescriptions is very low compared with the total prescriptions, ranging from
$0.006 \%$ to $0.07 \%$. Data on the differences in forgery rates between provinces with and without triplicate prescription programs are not available, but there has been a substantial national decline (approximately 50\% from 1994 to 1997), and this decline has been reflected in all provinces in the number of forgeries since 1994 (25).

\section{Thefts and losses}

Data compiled by the Addiction Research Foundation of Ontario in 1997 indicated that in 1994 codeine and oxycodone were the most frequently stolen opioids (23). To allow frequency of theft to be related to frequency of legitimate use, an estimate of the amount dispensed for each opioid was obtained by calculating an average prescription size for each drug and calculating the total units dispensed, based on IMS data (24) for the number of prescriptions for each drug. When the number of stolen units of each drug is expressed relative to the number of units dispensed (Table 4) the rates for each drug are quite similar. Any differences are probably not significant given the wide range in number of prescriptions and, therefore, units dispensed, of various opioids.

\section{CONCERNS OVER REGULATORY SANCTIONS}

It is a legitimate medical practice to prescribe opioid analgesics to patients provided that the patient record documents the following: the existence of a valid doctor-patient relationship, that the opioid analgesics are prescribed for a recognized therapeutic indication (pain is a recognized therapeutic indication for prescribing opioid analgesics) and the details of each prescription (ie, name, date, strength and number of dosage units of the drug). 
TABLE 4

Opioid thefts/losses in Canada, 1994

\begin{tabular}{|c|c|c|c|c|c|}
\hline Opioid & $\begin{array}{c}\text { Total prescriptions } \\
\text { dispensed }(\times 1000) \\
(24)\end{array}$ & $\begin{array}{c}\text { Average } \\
\text { prescription size }\end{array}$ & $\begin{array}{c}\text { Estimated units } \\
\text { dispensed }(\times \mathbf{1 0 0 0})\end{array}$ & $\begin{array}{c}\text { Estimated units } \\
\text { stolen/lost }(\times 1000) \\
(23)\end{array}$ & $\begin{array}{c}\text { Stolen/lost units as } \\
\text { percentage of total } \\
\text { dispensed }\end{array}$ \\
\hline Codeine & 7904 & 52 & 411,008 & 474 & 0.1 \\
\hline Oxycodone & 503 & 55 & 27,665 & 157 & 0.6 \\
\hline \multicolumn{6}{|l|}{ Hydrocodone } \\
\hline Tablets & 18 & 25 & 450 & 4 & 0.9 \\
\hline Liquid & 510 & $148 \mathrm{~mL}$ & $75,408 \mathrm{~mL}$ & $117 \mathrm{~mL}$ & 0.2 \\
\hline$*$ Total & 528 & 22 & 11616 & 27 & 0.2 \\
\hline \multicolumn{6}{|l|}{ Morphine } \\
\hline Sustained release & 173 & 75 & 12,975 & - & - \\
\hline Immediate release & 51 & 102 & 5202 & - & - \\
\hline Total & 224 & 81 & 18,177 & 58 & 0.3 \\
\hline Hydromorphone & 97 & 92 & 8924 & 35 & 0.4 \\
\hline Meperidine & 193 & 40 & 7720 & 35 & 0.5 \\
\hline Pentazocine & 128 & 55 & 7040 & 16 & 0.2 \\
\hline
\end{tabular}

*Each unit equals $5 \mathrm{mg}$. Data from references 23,24

A number of guidelines for the use of opioids in chronic noncancer pain provide additional advice on appropriate standards of practice. These include completion of a comprehensive diagnostic workup and assessment of pain etiology, documentation of failure of other treatments, use of screening tools to identify patients at risk of abuse, informed consent and/or establishment of a patient contract covering treatment goals, and expectations of both patient and physician.

However, concerns persist that even appropriate prescribing of opioids to patients with pain according to these criteria will lead to regulatory sanctions. In a recent study, physicians who were identified as frequent prescribers of opioid analgesics decreased their frequency of prescriptions by $33 \%$ when they were notified by the British Columbia College of Physicians and Surgeons of their 'excessive' prescribing and were requested to attend a one-day educational intervention seminar (26). The impact of this decrease in opioid use on pain control was not assessed in this study, leading some commentators to emphasize that the problem of under-treated pain must also be considered whenever initiatives directed at reducing opioid use are implemented (27).

\section{CLINICAL GUIDELINES}

To address physicians' concerns, a number of organizations have published guidelines or discussion papers for the appropriate use of opioids in patients with pain of nonmalignant origin (eg, the Alberta Medical Association [28], the Joint Consensus Statement of the American Pain Society and the American Academy of Pain Medicine, 1997 [29], the Probationary Section on Chronic Pain of the Ontario Medical Association [30] and the Canadian Pain Society [31]). These guidelines support the use of opioid agents in managing chronic pain in patients whose pain is not controlled by alternatives and indicate that addiction, tolerance and toxicity are not believed to be major issues when opioids are used as part of a pain management program. In contrast to the emerging practice in cancer pain management, for sequential trials of different opioids in patients who experience inadequate pain relief or dose-limiting toxicity with one opioid, there has been little attention to the benefit of opioid rotation in patients with chronic noncancer pain. This is clearly an area where further research is needed before guidelines can be developed. Additionally, the guidelines recommend important tools for screening/evaluating patients who may be potential opioid abusers, such as establishing patient contracts for the use of opioids as well as periodic monitoring of the efficacy of treatment. These guidelines emphasize that for chronic pain conditions, the goal of chronic opioid therapy is not the elimination of pain, (which may be impossible), but rather to control pain to a tolerable level. Long term treatment with analgesic medication should be administered if analgesics result in relief of pain, functional improvement or both.

\section{CONCLUSIONS}

There is increasing evidence that opioids can improve both pain and functional capacity in patients with chronic noncancer pain, although not all patients respond sufficiently to warrant ongoing opioid therapy. The vast majority of patients who are prescribed opioids are at no risk of addiction or becoming an abuser. Individuals who are at greater risk are those with a history of alcohol and/or drug abuse, and a simple, validated questionnaire can effectively identify these individuals so that they can be more closely monitored.

Based on estimates of thefts/losses and forged prescriptions, the opioids most likely to be abused in absolute terms are codeine and oxycodone. However, these are the most widely prescribed opioids, and when expressed relative to the number of units dispensed, the rates of forgery and theft are 
similar to those of other opioids. Surveys of street use indicate that stronger opioids such as morphine and hydromorphone are also abused, with the extent of abuse approximately reflecting availability as measured by the number of prescriptions.

Continuing educational efforts are required to ensure that fear of abuse or regulatory sanctions do not deter physicians from appropriately prescribing opioids to patients in legitimate need of pain relief, and that the difference between physical dependence and addiction is recognized. Fortunately, information and guidelines to assist physicians in the diagnosis and treatment of patients with noncancer pain, and methods to help physicians identify patients at risk of abuse are available.

ACKNOWLEDGEMENTS: The authors are grateful to Mr WB Jeffery for analysis of the opioid market data.

\section{REFERENCES}

1. Portenoy RK. Opioid therapy for chronic nonmalignant pain: a review of the critical issues. J Pain Symptom Manage 1996;11:203-17.

2. Zenz M, Strumpf M, Tryba M. Long-term oral opioid therapy in patients with chronic nonmalignant pain. J Pain Symptom Manage 1992;7:69-77.

3. Portenoy RK. Opioid therapy for chronic nonmalignant pain: current status. Prog Pain Res Manage 1994;1:247-87.

4. Moulin DE. Opioid analgesics for chronic nonmalignant pain. Can J CME 1996;2:137-43.

5. Reidenberg MM, Portenoy RK. The need for an open mind about the treatment of chronic nonmalignant pain. Clin Pharmacol Ther 1994;55:367-9.

6. Moulin DE, Iezzi A, Amireh R, Sharpe WKJ, Boyd D, Merskey H. Randomised trial of oral morphine for chronic noncancer pain. Lancet 1996;347:143-7.

7. Watson CPN, Babul N. Efficacy of oxycodone in neuropathic pain: a randomized trial in postherpetic neuralgia. Neurology 1998;50:1837-41.

8. Arkinstall W, Sandler A, Goughnour B, Babul N, Harsanyi Z, Darke AC. Efficacy of controlled-release codeine in chronic non-malignant pain: a randomized, placebo-controlled clinical trial. Pain 1995;62:169-78.

9. Hale ME, Speight KL, Harsanyi Z, et al. Efficacy of 12 hourly controlled-release codeine compared with as required dosing of acetaminophen plus codeine in patients with chronic low back pain. Pain Res Manage 1997;2:33-8.

10. Peloso P, Bellamy N, Bensen W, Thompson G, Babul N. A double blind randomized placebo controlled trial of controlled release codeine in osteoarthritis of hip and knee. J Rheumatol 1998;25:4. (Abst)

11. Caldwell JR, Hale ME, Boyd RE, et al. Treatment of osteoarthritis with controlled realease oxycodone or fixed combination oxycodone plus acetaminophen added to nonsteroidal anti-inflammatory drugs: a double blind, randomized, multicenter, placebo controlled trial. Gentlemen Rheumatol 1999;26:862-9.

12. Gardner-Nix J. Getting one up on chronic nonmalignant pain. Can J Diagn 1997;14:87-100.

13. American Psychiatric Association. Diagnostic and Statistical Manual of Mental Disorders, 4th edn: DSM-IV. Washington: American Psychiatric Association, 1994:78-85.

14. Savage SR. Long-term opioid therapy: assessment of consequences and risks. J Pain Symptom Manage 1996;11:274-86.

15. Portenoy RK. Chronic opioid therapy in nonmalignant pain. J Pain Symptom Manage 1990;5:S46-62.

16. Porter J, Jick H. Addiction rare in patients treated with narcotics. N Engl J Med 1980;302:123. (Lett)

17. Perry S, Heidrich G. Management of pain during debridement: a survey of U.S. burn units. Pain 1982;13:267-80.

18. Chabal C, Erjavec MK, Jacobson L, Mariano A, Chaney E. Prescription opiate abuse in chronic pain patients: clinical criteria, incidence, and predictors. Clin J Pain 1997;13:150-5.

19. Busto UE, Sproule BA, Knight K, Romach MK, Sellers EM. Severe dependence on oral opioids. Can J Clin Pharmacol 1998;5:23-8.

20. Coambs RB, Jarry JL, Santhiapillai AC, Abrahamsohn RV, Atance CM. The SISAP: A new screening instrument for identifying potential opioid abusers in the management of chronic nonmalignant pain within general medical practice. Pain Res Manage 1996;1:155-62.

21. Wesson DR, Ling W, Smith DE. Prescription of opioids for treatment of pain in patients with addictive disease. J Pain Symptom Manage 1993;8:289-96.

22. Sajan A, Corneil T, Grzybowski S. The street value of prescription drugs. CMAJ 1998; 159:139-42.

23. Single E, Williams B, McKenzie D. Canadian Profile: Alcohol, Tobacco and Other Drugs 1997. Toronto: Addiction Research Foundation, 1997:336-40

24. Canadian Compuscript, December 1994. IMS America, Plymouth Meeting, Pennsylvania.

25. Bureau of Drug Surveillance, Information Services Division, Ottawa Trends in Diversion of Controlled Substances. Ottawa: Therapeutic Products Programme, Health Canada, 1998.

26. Anderson JF, McEwan KL, Hrudey WP. Effectiveness of notification and group education in modifying prescribing of regulated analgesics. CMAJ 1996;154:31-9.

27. Goldman B. The news on the street: prescription drugs on the black market. CMAJ 1998;159:149-50.

28. Hagen N, Flynne P, Hays H, MacDonald N. Guidelines for managing chronic non-malignant pain. Opioids and other agents. Can Fam Physician 1995;41:49-53.

29. The use of opioids for the treatment of chronic pain - A consensus statement from American Academy of Pain Medicine and American Pain Society. Pain Res Manage 1997;2:126-8.

30. Use of opioid analgesics for the treatment of chronic pain of nonmalignant origin. A discussion paper from the Probationary Section on Chronic Pain of the Ontario Medical Association. Pain Res Manage 1997;2:231-7.

31. Use of opioid analgesics for the treatment of chronic noncancer pain. A consensus statement and guidelines from the Canadian Pain Society. Pain Res Manage 1998;3:197-208. 


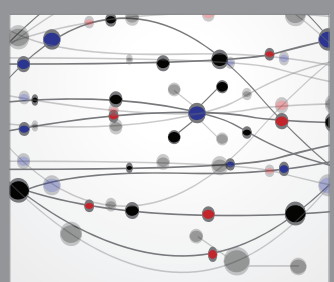

The Scientific World Journal
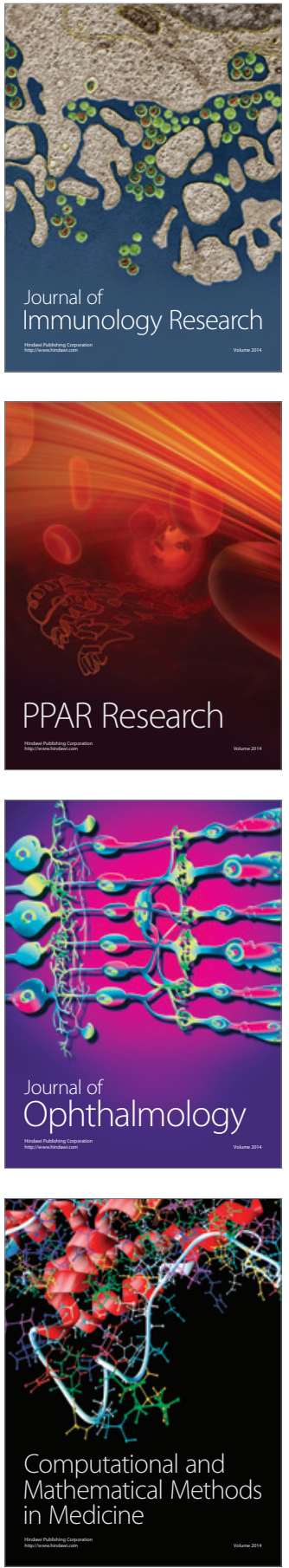

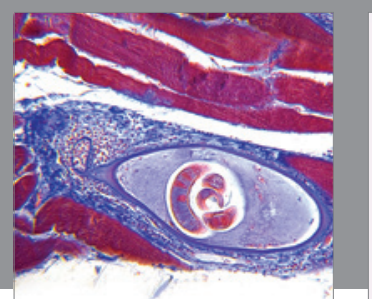

Gastroenterology Research and Practice

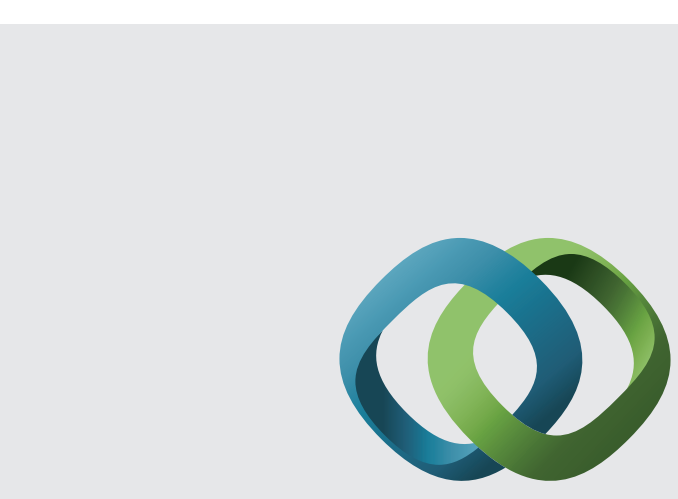

\section{Hindawi}

Submit your manuscripts at

http://www.hindawi.com
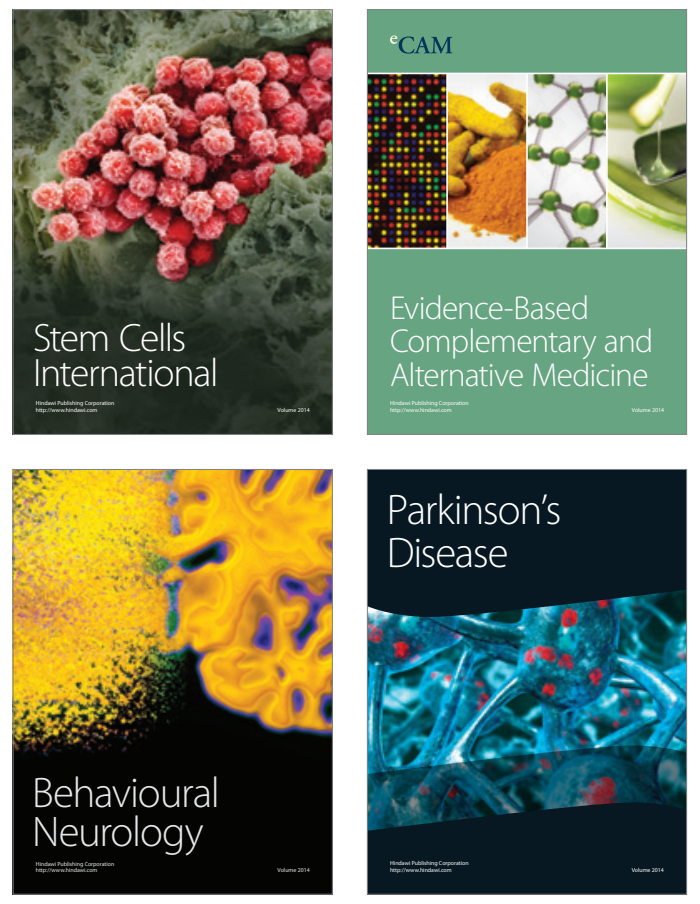
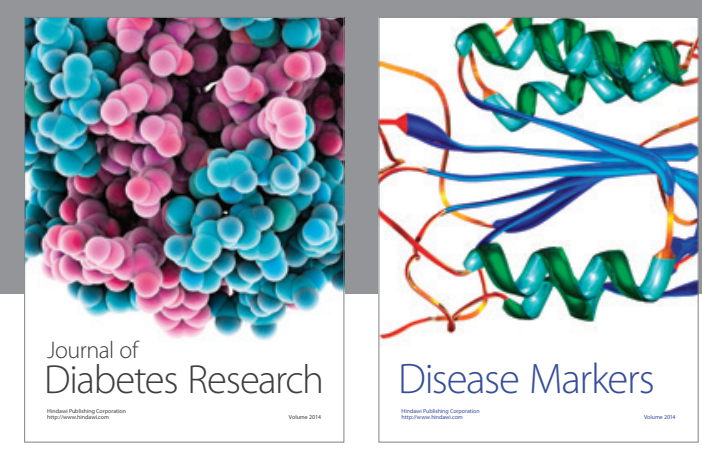

Disease Markers
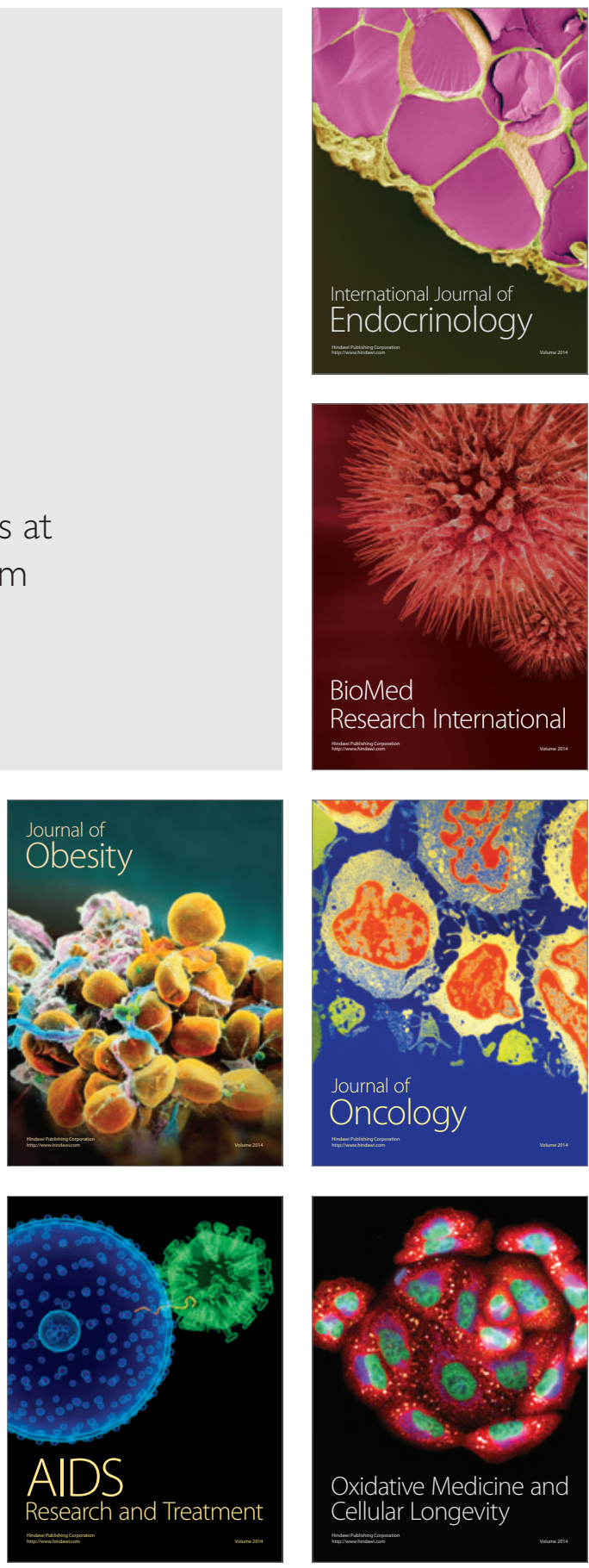